\title{
Eficiência da aplicação de nutrientes via semente e foliar na cultura do amendoim
}

\author{
Raphaela Maceió Silva ${ }^{1}$, Jeandson Silva Viana ${ }^{2}$, Edilma Pereira Gonçalves ${ }^{2}$, Guilherme Souza \\ de Moraes ${ }^{2}$
}

${ }^{1}$ Universidade Federal de Campina Grande, Campina Grande, Paraíba, Brasil. E-mail: maceiosilva@ hotmail.com

${ }^{2}$ Universidade Federal Rural de Pernambuco, Unidade Acadêmica de Garanhuns, Pernambuco, Brasil. E-mail: jeandsonsv@yahoo.com.br, edilmapg@hotmail.com, guilhermegsm08@hotmail.com

Recebido: 26/02/2017; Aceito: 20/03/2018.

\section{RESUMO}

$\mathrm{O}$ adequado suprimento de nutrientes é essencial para promover o crescimento e desenvolvimento das plantas e assegurar elevados níveis de produtividade das culturas. Este estudo teve como objetivo avaliar a eficiência da aplicação de cálcio $(\mathrm{Ca})$, boro $(\mathrm{B})$, cobalto $(\mathrm{Co})$ e molibdênio (Mo) nas sementes associado à aplicação foliar de $\mathrm{Ca}+\mathrm{B}$ em diferentes épocas na cultura do amendoim. $\mathrm{O}$ ensaio constituiu das seguintes aplicações de nutrientes: aplicação de Co, Mo, Ca, e B nas sementes associado a aplicação foliar de Ca e B aos 0, 17, 23, 29, 35 e 41 dias após a semeadura (DAS) e um tratamento adicional sem aplicação de nutrientes (controle). Os resultados foram submetidos à análise de variância e as médias agrupadas pelo teste de Scott-Knott, a 5\% de probabilidade. A aplicação dos nutrientes Co, Mo, Ca e B nas sementes em associação a aplicação foliar de $\mathrm{Ca}$ e B em diferentes épocas aumentou a formação de vagens e melhorou o desenvolvimento e a produtividade de vagens de amendoim.

Palavras-chave: Arachis hypogaea, fixação biológica de nitrogênio, absorção de nutrientes.

\section{Efficiency of nutrient application in seeds and leaves in the peanut crop}

\begin{abstract}
Adequate nutrient supply is essential to promote plant growth and development and ensure high levels of crop productivity. The objective of this study was to evaluate the efficiency of the application of calcium (Ca), boron (B), cobalt (Co) and molybdenum (Mo) in the seeds associated with foliar application of Ca and B at different application times in the peanut crop. In this assay the following nutrient applications were tested: application of $\mathrm{Co}, \mathrm{Mo}, \mathrm{Ca}$, and $\mathrm{B}$ in the seeds associated with foliar application of $\mathrm{Ca}$ and $\mathrm{B}$ at $0,17,23,29,35$ and 41 days after sowing (DAS) and one treatment without application of nutrients (control). The results were submitted to analysis of variance and the means grouped by the Scott-Knott test, at 5\% probability. The application of Co, Mo, Ca and $\mathrm{B}$ in the seeds in association with foliar application of $\mathrm{Ca}$ and $\mathrm{B}$ at different times increased the development of pods and improved the growth and productivity of peanut pods.
\end{abstract}

Key words: Arachis hypogaea, biological nitrogen fixation, nutrient uptake. 
O amendoim (Arachis hypogea L.) é uma cultura oleaginosa de grande importância socioeconômica no Brasil e no mundo. No Brasil, o cultivo de amendoim tem despertado o interesse, recente, dos podutores rurais devido às características edafoclimáticas e geográficas das diferentes regiões do país que favorecem o crescimento e desenvolvimento da cultura (RODRIGUES et al., 2016). Na região Nordeste, o amendoim é cultivado basicamente por pequenos e médios produtores, com áreas em torno de 3,3 mil hectare (CONAB, 2015), a qual se encontra em franca expansão devido ao incentivo da produção de óleo para o biodiesel.

O sucesso da produção de uma cultura está relacionado com o adequado suprimento de nutrientes, os quais são fundamentais para o crescimento e desenvolvimento da planta. A adubação foliar fundamenta-se na premissa que as folhas das plantas podem absorver nutrientes (BOARETTO et al., 2003). Absorção foliar consiste na entrada do nutriente na célula, e o transporte e movimento do nutriente do local de absorção para os outros órgãos dos vegetais. No entanto, são dois processos diferentes e podem acontecer ao mesmo tempo. Assim, a aplicação de nutrientes via semente e via foliar em diferentes épocas pode promover aumento de produtividade da cultura.

$\mathrm{O}$ amendoim depende da fixação biológica do nitrogênio (FBN) para a sua nutrição e o molibdênio (Mo), um micronutriente que desempenha papel fundamental na nutrição das plantas, pois sua função está relacionada com o metabolismo do nitrogênio $(\mathrm{N})$ fazendo parte de duas metaloenzimas: a nitrogenase, que participa na FBN e a redutase do nitrato, que atua na redução do nitrato à amônia na planta (ARAÚJO et al., 2008). O cálcio (Ca) é essencial para manter a integridade estrutural e funcional das membranas e da parede celular sendo indispensável para a germinação do grão de pólen e crescimento do tubo polínico; sintomas de deficiência se manifestam inicialmente nas folhas mais novas e várias espécies mostram sintomas no fruto (MALAVOLTA, 2006).

É necessário que se desperte o interesse dos produtores rurais em utilizar a aplicação foliar de nutrientes; é primordial que se tenha conhecimento do momento adequado ou época ideal para a aplicação de cada um dos nutrientes, os quais são primordiais para melhorar a produtividade.

Em função do exposto, o trabalho teve como objetivo avaliar a eficiência da aplicação de cálcio $(\mathrm{Ca})$, boro (B), cobalto (Co) e molibdênio (Mo) nas sementes associado à aplicação foliar de $\mathrm{Ca}+\mathrm{B}$ em diferentes épocas na cultura do amendoim.

$\mathrm{O}$ experimento foi realizado em área experimental da Universidade Federal Rural de Pernambuco, em Garanhuns, PE (08 $53^{\prime} 25^{\prime \prime}$ S e $36^{\circ} 29^{\prime} 34^{\prime \prime}$ W e altitude média de $896 \mathrm{~m}$ ). O clima predominante na região é o tropical. A temperatura média anual é de $20,4{ }^{\circ} \mathrm{C}$ e umidade relativa média anual de $80 \%$, de acordo com o Instituto de Tecnologia de Pernambuco (ITPE). Os dados referentes às temperaturas máximas, mínimas e umidade relativa do período da condução do experimento são mostrados na Figura 1. A temperatura máxima durante a condução do experimento foi de 30 ${ }^{\circ} \mathrm{C}$, a temperatura mínima foi de $19{ }^{\circ} \mathrm{C}$ e a umidade relativa média de $88 \%$.

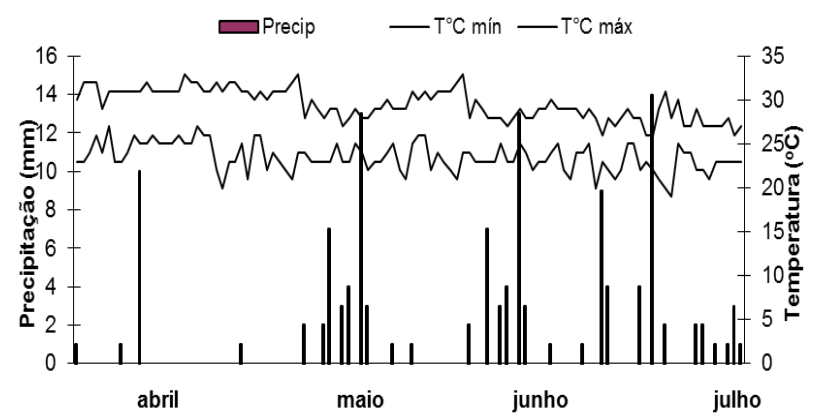

Figura 1. Valores diários de temperatura máxima, mínima e precipitação. Fonte: INMET- Instituto Nacional de Meteorologia

O delineamento experimental foi o de blocos ao acaso, com sete tratamentos e quatro repetições. Os tratamentos estudados são mostrados na Tabela 1. Para o tratamento das sementes, foram utilizadas as doses de 2,61 g de $\mathrm{Ca}+\mathrm{B}$ e $1,5 \mathrm{~g}$ de Co+Mo. A fonte de cálcio e boro utilizada foi o fertilizante comercial da Altagro ${ }^{\circledR}$ nutrição de plantas e como fonte de Co+Mo foi utilizado o fertilizante comercial da Ray Nitro ${ }^{\circledR}$.

Para a semeadura foram utilizadas sementes da cultivar BR1. As sementes foram inoculadas com inoculante comercial contendo as estirpes de Bradiryzobium sp. $\quad\left(\right.$ Biomax $^{\circledR}$ Premium Turfa Amendoim), na dose de $120 \mathrm{~g}$ para $40 \mathrm{~kg}$ de sementes, misturadas com $10 \mathrm{~g}$ de açúcar e $300 \mathrm{~mL}$ de água por 80 $\mathrm{kg}$ de sementes. Cada parcela foi formada por três linhas de amendoim de $2,0 \mathrm{~m}$ de comprimento, sendo considerado como área útil 1,0 $\mathrm{m}^{2}$, compreendendo uma área total de $128 \mathrm{~m}^{2}$. Foram semeadas 16 sementes por metro.

A adubação de base foi realizada no sulco da semeadura com $80 \mathrm{~kg} \mathrm{ha}^{-1}$ de $\mathrm{P}_{2} \mathrm{O}_{5}$ (superfosfato simples) e $40 \mathrm{~kg} \mathrm{ha}^{-1}$ de $\mathrm{K}_{2} \mathrm{O}$ (cloreto de potássio) de acordo com a análise química do solo. O controle de plantas daninhas foi realizado manualmente, não sendo necessário realizar o controle de pragas e doenças; empregou-se irrigação por aspersão nos períodos de estiagem.

O solo foi classificado como areno-argiloso de acordo com análises efetuadas no Laboratório de Física do Solo - UFRPE/UAG. As principais propriedades físico-químicas do solo são mostradas na Tabela 2. 
Tabela 1. Descrição dos tratamentos de aplicação de nutrientes nas semente associado ou não a aplicação foliar na cultura do amendoim

\begin{tabular}{clc}
\hline Tratamentos & Descrição dos tratamentos & DAS \\
\hline 1 & Co+Mo e Ca+B nas sementes & - \\
2 & Co+Mo e Ca+B nas sementes + aplicação foliar de Ca+B & 17 \\
3 & Co+Mo e Ca+B nas sementes + aplicação foliar de Ca+B & 23 \\
4 & Co+Mo e Ca+B nas sementes + aplicação foliar de Ca+B & 29 \\
5 & Co+Mo e Ca+B nas sementes + aplicação foliar de Ca+B & 35 \\
6 & Co+Mo e Ca+B nas sementes + aplicação foliar de Ca+B & 41 \\
7 & Controle (sem aplicação de nutrientes) & - \\
\hline
\end{tabular}

DAS: dias após a semeadura para a aplicação foliar de $\mathrm{Ca}+\mathrm{B}$.

Tabela 2. Propriedades químicas e granulométricas do solo da área experimental utilizada para a semeadura da cultura do amendoim

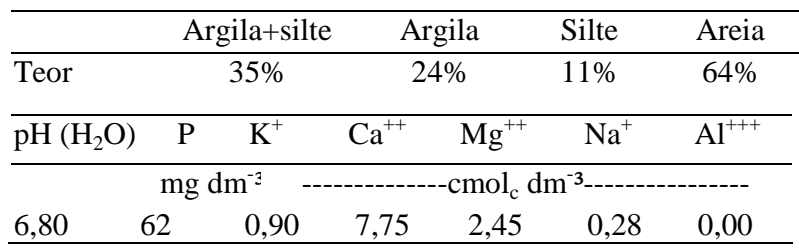

Foram coletadas 10 plantas por parcela no estádio fenológico R8, no ponto de maturação para colheita e realizadas as seguintes avaliações: i) número de vagens por planta (NVP), obtidas por meio de contagem; ii) número de vagens chochas por planta (NVCP) obtidos por meio de contagens de vagens chochas; iii) massa de vagens por planta (MVP) utilizadas as 10 plantas das quais retirou-se as vagens e, posteriormente, pesadas em balança analítica; iv) massa total de vagens (MTV), obtida por meio do peso total das vagens da área total, pesadas em balança analítica; v) altura de planta (AP), determinada com auxílio de régua graduada em $(\mathrm{cm})$ da superfície do solo até a extremidade da haste principal ao final do ciclo da cultura aos 90 dias; vi) matéria fresca (MF), foi obtida por meio da pesagem da matéria fresca da parte aérea em balança analítica; vii) Fitomassa (FTM), obtida pela pesagem de todas as plantas de cada tratamento separadamente, incluindo as vagens.

Os resultados foram submetidos à análise de variância e as médias foram agrupadas pelo teste de Scott-Knott, a 5\% de probabilidade.

A aplicação de nutrientes nas sementes em combinação com a aplicação foliar de $\mathrm{Ca}$ e $\mathrm{B}$ influenciou significativamente $(\mathrm{p}<0,05)$ o número de vagens (NVP), massa de vagens (MVP) e massa total de vagens (MTV) de amendoim (Tabela 3). A aplicação de nutrientes nas sementes associado a aplicação foliar de $\mathrm{Ca}$ e B resultou no maior número de vagens por planta, massa de vagens por planta e massa total de vagens em comparação ao tratamento controle (Tabela 3). Estes resultados reportam que a aplicação de nutrientes quer na semente ou via foliar é de fundamental importância para a formação e o desenvolvimento das vagens das plantas de amendoim. Segundo Bolonhezi (2005), o número de vagens por planta é o componente da produção mais afetado pelo aumento da população de plantas, logo há redução, compensada pelo maior número de vagens por área. Em trabalho realizado por Belivaqua et al. (2002), a aplicação foliar de Ca e B resultou no aumento do número de vagens por planta e do número de sementes por vagem.

Segundo Bevilaqua et al. (2002), a aplicação foliar de $\mathrm{Ca}$ e $\mathrm{B}$ pode aumentar o número de vagens por planta, grãos por vagem e a massa de sementes por planta, quando aplicados na fase da floração na cultivar do amendoim. De acordo com Garcia e Hanway (1976), a adubação foliar tem sido recomendada para aumentar ou manter a concentração de nutrientes nas folhas, no período de enchimento de grãos, porque nessa fase, a absorção de nutrientes pelas raízes é praticamente nula. Assim pode-se observar uma relação entre o conteúdo de nutrientes na planta e o metabolismo que forma as estruturas reprodutivas e consequentemente, aumento na produtividade.

Quanto ao número de vagens chochas não houve diferenças significativas $(p>0,05)$ entre os diferentes tratamentos estudados (Tabela 3). Portanto, verifica-se que a aplicação foliar de $\mathrm{Ca}$ e $\mathrm{B}$ em diferentes épocas não tem efeito na redução das vagens chochas na cultura do amendoim. De acordo com Folini et al. (2008), a deficiência de $\mathrm{Ca}$, além de outros efeitos adversos, propicia o surgimento de vagens chochas e com casca frágeis, comprometendo a produtividade e a qualidade dos grãos de amendoim.

A aplicação de nutrientes nas sementes em combinação com as diferentes épocas de aplicação foliar de Ca e B influenciou significativamente $(p<0,05)$ a altura de planta (AP) e a massa fresca (MF) da parte aérea das plantas de amendoim (Tabela 4). A aplicação foliar de $\mathrm{Ca}$ e $\mathrm{B}$ aos 35 dias após a emergência resultou em plantas de amendoim de menor altura em comparação aos demais tratamentos (Tabela 4). 
Tabela 3. Número de vagens (NVP), número de vagens chochas (NVCP), massa de vagens (MVP) e massa total de vagens (MTV) de amendoim em resposta a aplicação dos nutrientes (Co, Mo, Ca e B) nas sementes associada a diferentes épocas de aplicação foliar de Ca e B

\begin{tabular}{ccccc}
\hline Tratamentos & NVP & $\begin{array}{c}\text { NVCP } \\
(\mathrm{g})\end{array}$ & $\begin{array}{c}\text { MVP } \\
(\mathrm{g})\end{array}$ & $\begin{array}{c}\text { MTV } \\
\left(\mathrm{kg} \mathrm{ha}^{-1}\right)\end{array}$ \\
\hline TS & $6,45 \mathrm{a}$ & 2,80 & $32,1 \mathrm{a}$ & $1.646 \mathrm{a}$ \\
$\mathrm{TS}+\mathrm{AF} 17$ & $4,32 \mathrm{a}$ & 2,62 & $12,4 \mathrm{a}$ & $2.116 \mathrm{a}$ \\
$\mathrm{TS}+\mathrm{AF} 23$ & $4,87 \mathrm{a}$ & 1,50 & $22,2 \mathrm{a}$ & $1.921 \mathrm{a}$ \\
$\mathrm{TS}+\mathrm{AF} 29$ & $5,60 \mathrm{a}$ & 2,85 & $20,5 \mathrm{a}$ & $1.677 \mathrm{a}$ \\
$\mathrm{TS}+\mathrm{AF} 35$ & $5,12 \mathrm{a}$ & 2,03 & $22,8 \mathrm{a}$ & $1.803 \mathrm{a}$ \\
TS + AF41 & $4,70 \mathrm{a}$ & 2,50 & $26,1 \mathrm{a}$ & $1.876 \mathrm{a}$ \\
Controle & $3,92 \mathrm{~b}$ & 1,67 & $4,8 \mathrm{~b}$ & $1.430 \mathrm{~b}$ \\
\hline Média & 4,99 & 2,28 & 20,13 & 1.781 \\
\hline CV $(\%)$ & 39,66 & 57,04 & 73,00 & 14,28 \\
\hline
\end{tabular}

TS: tratamento das sementes com Co+Mo e Ca+B. AF: Aplicação foliar de $\mathrm{Ca}+\mathrm{B}$ aos 17, 23, 29, 35 e 41 dias após a semeadura (DAS). Controle (sem aplicação de nutrientes). Médias seguidas de mesma letra, não diferem entre si pelo teste de Scott-Knott ao nível de 5\%.

Tabela 4. Altura de planta (AP), massa fresca (MF) e fitomassa total (FTM) das plantas de amendoim em resposta a aplicação dos nutrientes (Co, Mo, Ca e B) nas sementes associada a diferentes épocas de aplicação foliar de Ca e B

\begin{tabular}{lccc}
\hline Tratamentos & AP $(\mathrm{cm})$ & MF $(\mathrm{g})$ & FTM $(\mathrm{kg})$ \\
\hline TS & $10,85 \mathrm{a}$ & $133,8 \mathrm{~b}$ & 3.775 \\
TS + AF17 & $10,76 \mathrm{a}$ & $144,3 \mathrm{~b}$ & 2.224 \\
TS + AF23 & $10,38 \mathrm{a}$ & $224,0 \mathrm{a}$ & 3.177 \\
TS + AF29 & $12,91 \mathrm{a}$ & $181,8 \mathrm{~b}$ & 2.817 \\
TS + AF35 & $7,80 \mathrm{~b}$ & $185,5 \mathrm{~b}$ & 2.758 \\
TS + AF41 & $9,36 \mathrm{a}$ & $220,1 \mathrm{a}$ & 2.966 \\
Controle & $9,45 \mathrm{a}$ & $182,4 \mathrm{~b}$ & 3.886 \\
\hline Médias & 10,21 & 181,7 & 3.086 \\
\hline CV $(\%)$ & 16,14 & 18,04 & 36,51 \\
\hline
\end{tabular}

TS: tratamento das sementes com Co+Mo e Ca+B. AF: Aplicação foliar de $\mathrm{Ca}+\mathrm{B}$ aos 17, 23, 29, 35 e 41 dias após a semeadura (DAS). Controle (sem aplicação de nutrientes). Médias seguidas de mesma letra, não diferem entre si pelo teste de Scott-Knott ao nível de 5\%.

De acordo com Boareto et al. (2003), um dos critérios para avaliar o efeito da velocidade de absorção de nutrientes pelas folhas é o aumento do crescimento da planta, quantificado por meio da absorção foliar dos nutrientes. Segundo pesquisas realizadas por Malavolta (1974) com ensaios na cultura da soja, contatou-se que as pulverizações foliares apresentam boa resposta.

Tendo em vista a baixa mobilidade de alguns nutrientes, se faz necessária a aplicação desses nutrientes nas sementes em associação à aplicação foliar durante os estágios vegetativos da cultura. Essa prática ratifica a inexistência de nutriente no solo e certifica a eficiência para o desenvolvimento e produtividade da cultura. Peske et al. (2005), verificaram a viabilidade da aplicação do Mo mediante pulverização foliar no início da floração.
A aplicação foliar de Ca e B aos 23 e 42 dias após a emergência resultou em maior massa fresca da parte aérea das plantas em comparação aos demais tratamentos (Tabela 4). De acordo com Tasso Junior et al. (2004), o B tem por função impedir baixos níveis de fecundação e está presente nos fitohormônios, influenciando a reprodução, germinação do grão de pólen e crescimento do tubo polínico. Segundo Malavolta (2006), o B é um elemento importante para o crescimento vegetativo, sendo a parede celular e a membrana citoplasmática dos principais locais onde atua.

As diferentes épocas de aplicação foliar de $\mathrm{Ca}$ e B não influenciaram significativamente $(p>0,05)$ a fitomassa total das plantas de amendoim (Tabela 4). A produção da fitomassa pode ser aproveitada pelo produtor rural como adubação verde, pois são capazes de realizar a fixação biológica do nitrogênio atmosférico através de uma associação específica de microrganismos que colonizam as raízes das plantas com Rizobium, favorecendo o desenvolvimento da próxima cultura. Fato este, verificado em trabalhos realizados por Castro et al. (2004) com a utilização de leguminosas na adubação verde em pré-cultivo e consórcio, observando um contribuição no fornecimento de $\mathrm{N}$ para a cultura da berinjela. Vazquez et al. (2005) ao estudarem o efeito da aplicação de Co e Mo via semente ou foliar na qualidade fisiológica das sementes de amendoim, concluíram que o uso desses nutrientes não interferiu na qualidade fisiológica das sementes produzidas.

A aplicação dos nutrientes $\mathrm{Co}$, Mo, Ca e B nas sementes em associação à aplicação foliar de Ca e B em diferentes épocas aumentou a formação de vagens e melhorou o desenvolvimento e a produtividade de vagens de amendoim.

\section{Referências Bibliográficas}

ARAÚJO, G. A. A.; SILVA, A. A.; THOMAS, A.; ROCHA, P. R. R. Misturas de herbicidas com adubo molíbdico na cultura do Feijão. Planta Daninha, Viçosa-MG, v. 26, n. 1, p. 237-247, 2008.

BEVILAQUA, G. A. P.; SILVA FILHO, P. M.; POSSENTI, J. C. Aplicação foliar de cálcio e boro e componentes de rendimento e qualidade de sementes de soja. Ciência Rural, Santa Maria-RS, v. 32, n. 1, p. 32-34, 2002.

BOARETTO, A. E.; MURAOKA, T.; BOARETTO, R. M. Absorção e translocação de $\mathrm{Mn}$, Zn e B aplicados via foliar em Citros. Laranja, Cordeirópolis - SP, v. 24, n. 1, p. 177197, 2003

BOLONHEZI, D.; GODOY, I. J.; SANTOS, R. C. Manejo Cultural do amendoim. In: SANTOS, R. C. O Agronegócio do Amendoim no Brasil, Campina Grande-PB: Embrapa Algodão, 2005. p. 193-244. 
CONAB. Companhia Nacional de Abastecimento. Acompanhamento da Safra Brasileira. Safra 2015-2016, v. 3, n. 3, 2015.

CASTRO, C. M..; ALVES, B. J. R.; ALMEIDA, D. L.; ROBEIRO, R. L. D. Adubação verde como fonte de nitrogênio para a cultura da berinjela em sistema orgânico. Pesquisa Agropecuária Brasileira, Brasília-DF, v. 39, n. 8, p. 779-785, 2004.

FOLONI, J. S. S.; SANTOS, D. H.; SILVA, P. H. Resposta do amendoim a doses excessivas de calcário. Colloquium Agrariae, Oeste Paulista-SP, v. 4, n. 1, p. 9-14, 2008.

GARCIA , R. L.; HANWAY, J. J. Foliar fertilization of soybeans during the seed-filling period. Agronomy Journal, Guilford Road-Madison, v. 68, n. 4, p. 653-657, 1976.

MALAVOLTA, E. Nutrição de plantas. In: FERRI, M. G. (org.) Fisiologia Vegetal. São Paulo-SP: EDUSP, 2006. v. 1, $400 \mathrm{p}$.
PESKE, S. T.; TRIGO, L. F. N.; OUTOMURO, M. F. O. Soya: Producción y Tecnologia. 2. ed. Pelotas-RS: Editora Universidade Federal de Pelotas, 2005. 574 p.

RODRIGUES, L. G. S. M.; RODRIGUES, F. M.; OLIVEIRA, E. M.; VIEIRA, V. B.; ARÉVALO, A. M.; VIROLI, S. L. M. Amendoim (Arachis sp.) como fonte na matriz energética brasileira. Journal of Bioenergy and Food Science. Macapá-AP, v. 3, n. 3, p. 178-190, 2016.

TASSO JUNIOR, L. C.; MARQUES, M. O.; NOGUEIRA, G. A. A cultura do amendoim. Jaboticabal-SP: FUNEP, 2004. $220 \mathrm{p}$.

VAZQUEZ, G. H.; CARVALHO, N. M.; CARNEIRO, L. O.; GARCIA, F. P. Efeito de molibdênio e cobalto sobre a nodulação, produção e qualidade fisiológica de sementes de amendoim (Arachis hypogaea). Informativo Abrates. Brasília-DF, v. 15, n. 1, p. 107, 2005. 